\title{
A contaminação do rio Guaraguaçu (Litoral do Paraná): limites e riscos ao desenvolvimento territorial regional
}

\author{
Guaraguaçu river contamination (Paraná Coast): limits and risks to regional territorial \\ development
}

\author{
Gustavo Augusto Santos Elste ${ }^{1}$ \\ Giovanna de Andrade Zanlorenci ${ }^{2}$ \\ Luiz Fernando de Carli Lautert ${ }^{3}$ \\ Mariana Gallucci Nazário ${ }^{4}$ \\ Paulo Henrique Carneiro Marques ${ }^{5}$ \\ Juliana Quadros
}

\section{Resumo}

Este estudo diagnostica um impacto ambiental de grande magnitude que ocorre na Bacia do Rio Guaraguaçu, importante rio de planície costeira, tanto pela sua rica biodiversidade e estado de conservação, quanto pelos serviços ambientais que oferece ao território. Trata-se da contaminação do rio Pery, afluente que recebe a maior parte da carga orgânica dos esgotos e do aterro dos municípios de Pontal do Paraná e Matinhos. Dados de qualidade das águas superficiais evidenciaram o alto grau de contaminação que determina alteração do contínuo fluvial, com grandes consequências ecossistemas, e grande risco à saúde ambiental das populações humanas que ali vivem. Os resultados são discutidos em função da magnitude deste impacto, e dos cenários futuros determinados pelos principais planos de desenvolvimento territorial e políticas públicas propostos para a região.

Palavras-chave: Análise Ambiental. Bacia Hidrográfica. Ecologia de Rios. Qualidade da Água.

\begin{abstract}
This study diagnoses a major environmental impact that occurs in the Guaraguaçu River Basin, an important coastal plain river, both for its rich biodiversity and conservation status, as well as the environmental services it offers to the territory. It's about the contamination of the Pery river, a tributary that receives most of the organic load from the sewers and the landfill of the cities of Pontal do Paraná and Matinhos. Surface water quality data showed a high degree of contamination that determines alteration of the river continuum, with great consequences for ecosystems, and great risk to the environmental health of the human populations that live there. The results are discussed according to the magnitude of this impact, and the future scenarios determined by the main territorial development plans and public policies proposed for the region.
\end{abstract}

Keywords: Environmental Analysis. Hydrographic Basin. River Ecology. Water Quality.

\footnotetext{
${ }^{1}$ Gestor Ambiental. Mestrando no Programa de Pós-Graduação em Desenvolvimento Territorial Sustentável (PPGDTS) da Universidade Federal do Paraná (UFPR), Setor Litoral. E-mail: santoselste@ gmail.com;

${ }^{2}$ Gestora Ambiental. Mestranda no PPGDTS/UFPR. E-mail: giovannazanlorenci@ gmail.com;

3 Doutor em Geografia. Professor do Programa de Pós-Graduação em Rede Nacional para Ensino das Ciências Ambientais. UFPR - Setor Litoral. E-mail: luizlautert@ufpr.br;

${ }^{4}$ Mestre em Geoquímica Ambiental. Técnica do Laboratório de Análises Ambientais. UFPR - Setor Litoral. E-mail: mari.nazario@ufpr.br;

${ }^{5}$ Doutor em Ecologia e Recursos Naturais. Professor da UFPR - Setor Litoral. E-mail: phcm@ufpr.br;

${ }^{6}$ Doutora em Zoologia. Professora do PPGDTS/UFPR. E-mail: quadros.juliana@ hotmail.com.
} 


\section{Introdução}

A água é um componente fundamental para dinâmica dos ecossistemas e manutenção da vida no planeta, sendo também considerada um dos recursos mais relevantes e limitantes ao desenvolvimento ambiental, social e econômico de um país ou região. Privilegiado neste cenário, o Brasil possui em seu território aproximadamente $12 \%$ da água doce disponível no mundo. Entretanto, as mudanças climáticas, as mudanças no uso do solo, a fragmentação de ecossistemas e a poluição, têm impactado na qualidade da água e causado ameaças aos recursos hídricos (PIRES et al., 2019). A Mata Atlântica é o bioma das florestas ombrófilas (úmidas), caracterizado por suas altas taxas de pluviosidade (RODERJAN et al., 2002). Entretanto este fato causa falsa impressão quanto a disponibilidade e a qualidade de suas águas, uma vez que o bioma é historicamente o mais pressionado por atividades antrópicas, como: o desmatamento, a caça, o crescimento demográfico e atividades produtiva industrial (DEAN, 1996; REZENDE et al., 2018). O relatório da qualidade da água em bacias hidrográficas da Mata Atlântica apresentado pelo projeto Observando os Rios, realizado entre 2016 e 2017 e comparado com os padrões de qualidade do CONAMA, apontou que apenas $2,5 \%$ dos corpos hídricos analisados se enquadram na categoria boa, sendo que $70 \%$ enquadram-se na categoria regular, $26,3 \%$ na categoria ruim e 1,3\% na categoria péssimo, não apresentando nenhum resultado na categoria ótimo (FUNDAÇÃO SOS MATA ATLÂNTICA, 2017).

O Litoral do Paraná se destaca, devido aos altos índices pluviométricos, que ultrapassam 2.000 $\mathrm{mm} / \mathrm{ano}$, com chuvas bem distribuídas no período sendo as maiores concentrações nos meses de janeiro e fevereiro (ITCG, 2008; VANHONI; MENDONÇA, 2008). Entretanto, a alta pluviosidade da região não representa sua disponibilidade, ou seja, a capacidade de retenção da água no ambiente hidrográfico e, nem tão pouco representa a qualidade da água neste ambiente.

Podemos afirmar que a maioria dos estudos recentes que abordam a qualidade dos ambientes aquáticos continentais no Litoral do Paraná demonstram a grande fragilidade ambiental das bacias hidrográficas, tanto nas regiões serranas quanto na planície costeira, em contraposição à alta pluviosidade e disponibilidade hídrica. De acordo com Miretzki (2017), o município de Paranaguá atravessa um período que antecede a sua crise hídrica, com proporções que poderão comprometer o seu abastecimento. A autora considera que o aumento da demanda e falta de gestão eficiente deste recurso tem gerado significativos impactos aos mananciais que abastecem o município, representados pela expansão industrial sobre áreas de mananciais, estresse e escassez de água em razão das 
alterações na disponibilidade (aumento de demanda) e consequentemente, o aumento no potencial de poluição aos recursos hídricos da região. Marques (2017) ressalta que os mananciais dos municípios de Matinhos, Paranaguá e Pontal do Paraná enfrentam pressões demográficas, em virtude das altas taxas de crescimento populacional residente, população flutuante (turismo) e expansão da indústria portuária, atividades que repercutem na modificação do uso do solo e aumento da demanda hídrica. O autor aborda a fragilidade destes mananciais relacionados a geomorfologia das bacias, a suscetibilidade à erosão e movimentos de massa na região serrana, bem como a estrutura dos solos na planície costeira, em que a alta permeabilidade e o lençol freático próximo da superfície potencializam os processos de assoreamento e contaminação.

Um dos principais óbices aos processos de planejamento e desenvolvimento territorial sustentável é falta de iniciativas e mesmo de estudos que consigam operar na interface entre as pressões econômicas, políticas e sociais que dirigem tais processo e suas consequências deletérias sobre a própria qualidade de vida, uma vez que são abordados de forma fragmentada: estudos sobre capacidade de suporte e serviços ecossistêmicos geralmente estão dissociados dos estudos socioeconômicos; da mesma forma, políticas públicas que pretendem a conservação, monitoramento e prevenção de riscos ambientais, estão dissociadas das políticas de desenvolvimento territorial, sendo frequentemente tratados por órgãos ou instâncias decisórias distintas, reforçando uma ideia de antagonismo destes processos. Analisando alguns dos principais instrumentos de gestão ambiental e territorial que incidem sobre a região, tais como os planos diretores municipais, estudos de impacto ambiental, e planos de desenvolvimento como a "faixa de infraestrutura" interligando polos de desenvolvimento portuário nos municípios de Pontal do Paraná e Paranaguá, percebemos que questões como saneamento ou contaminação ambiental são frequentemente negligenciados, como se fossem uma espécie de "custo inevitável” de um pretenso desenvolvimento econômico.

Neste sentido, o presente artigo pretende diagnosticar e analisar um caso grave de contaminação ambiental que bacia do rio Guaraguaçu, buscando a análise de suas causas e consequências, frente aos principais processos de planejamento ambiental em nível regional. Os efeitos dos efluentes de um aterro sanitário e dos efluentes domésticos difusos sobre o contínuo fluvial do rio Guaraguaçu, o mais importante rio de planície costeira no litoral do Paraná, são estudados do ponto de vista da ecologia de ecossistemas, com dados originais de qualidade das águas que evidenciam, qualificam e denunciam este grave problema socioambiental. Ao mesmo tempo, são evidenciados e discutidos os limites e riscos aos planos de desenvolvimento territorial, caso esta dimensão sanitária/ambiental não seja incorporado aos processos de planejamento em curso. Por fim, são analisadas as dificuldades de integrar as principais políticas públicas que influenciam o processo: 
O recém aprovado Plano de Bacia Litorânea (INSTITUTO ÁGUAS PARANÁ, 2019), que estabeleceu enquadramento dos corpos d'água; O Zoneamento Ecológico Econômico (ZEE-PR); os Planos de Manejo das Unidades de Conservação; Os Planos Diretores de Desenvolvimento municipal e o projeto de desenvolvimento regional denominado "Faixa de Infraestrutura de Pontal do Paraná" que pretende o fortalecimento da atividade portuária e prevê um grande incremento populacional para a região.

Nos últimos anos, tem se verificado várias denúncias a partir de moradores do local, pescadores, turistas e pesquisadores, chamando a atenção para um possível esgotamento da capacidade deste aterro sanitário, já próxima ao seu limite, bem como a contaminação do rio Pery e do rio Guaraguaçu. Relatos observam o mau cheiro, eutrofização, e até a formação de manchas superficiais de gordura nos trechos do rio próximos ao aterro, e Pescadores também relatam alterações na quantidade e qualidade do pescado. As denúncias deram origem em 2018 a uma ação civil pública contra as prefeituras participantes do consórcio, exigindo um plano para superação do problema (CORREIO DO LITORAL, 2018). A falta de dados recentes sobre a qualidade das águas na região motivou a realização deste estudo, sendo seu desenho amostral planejado para avaliar os possíveis impactos de efluentes não controlados no curso principal do rio Guaraguaçu. A partir de estudos anteriores deste grupo de pesquisa, e também da ocorrência de denúncias e reclamações feitas a partir de moradores e associações da região quanto a um possível "vazamento" de efluentes do aterro sanitário. Assim, elaboramos um desenho amostral específico para os seguintes objetivos: a) analisar dados de qualidade da água e caracterizar o ambiente aquático, com destaque aos indicadores de poluição sanitária; b) descrever o efeito dos efluentes antropogênicos aportados pelo rio Pery ao contínuo fluvial do rio Guaraguaçu, a partir de análises de qualidade de água; c) discutir o efeito desta fonte de contaminação, tendo em vista a importância ecossistêmica deste rio, bem como dos serviços ambientais que desempenha para a região; d) discutir as implicações deste grave problema ambiental em função das políticas públicas e processos de desenvolvimento territorial em curso.

\section{Material e métodos}

\section{Área de estudo}

Antes de desaguar na Baía de Paranaguá, as águas do rio Guaraguaçu percorrem três municípios litorâneos, Matinhos, Paranaguá e Pontal do Paraná (Figura 1). Atravessa extensa região de Floresta Ombrófila Densa de Terras Baixas, unidade fitogeográfica de Mata Atlântica, conhecida por sua complexa e heterogênea biodiversidade (RODERJAN et al., 2002; PIRES, 2005). A bacia do 
Guaraguaçu tem área de aproximadamente $280 \mathrm{~km}^{2}$, é a $4^{\mathrm{a}}$ maior sub bacia do Atlântico Sul Paranaense e, por abranger grande parte dos mananciais de abastecimento de 3 dos 7 municípios do Litoral Paranaense, representa grande relevância para a sustentabilidade econômica e bem estar da população litorânea (ZEE, 2016). Abriga três unidades de conservação (PARNA de SaintHilaire/Lange, APA de Guaratuba e ESEC do Guaraguaçu), e faz entorno com duas terras indígenas (Sambaqui e Ilha da Cotinga) habitadas pela etnia Guarani, que de acordo com Ladeira (2008), expressam seu modo de vida (economia, cultura e religião) com intrínseca relação de identidade com o território. O rio Guaraguaçu está inserido sobre a Planície Litorânea, as quais abrigam significativas paisagens caracterizada pela fragilidade ambiental com Formação Pioneira de Influência Fluvial, como caxetais, brejos e várzeas (BIGARELLA, 2001; AB'SABER, 2003).

Abastecida pelas microbacias dos rios Brejatuba, Pombas, Cambará, Cachoeirinha, Colônia Pereira, entre outros, localizadas na vertente oceânica da Serra da Prata (Parque Nacional de SaintHilaire/Lange), a bacia desempenha importantes serviços ambientais. O principal é o de manancial de abastecimento público, suprindo as cidades de Matinhos e Pontal do Paraná, servindo também como corpo receptor e diluidor dos efluentes domésticos destes municípios, tanto a partir das estações de tratamento de esgoto, quanto da poluição difusa produzida pela parcela da população que ainda não está atendida por redes de esgoto. Os efluentes, tratados ou não, são despejados um uma complexa rede de canais artificiais construídos durante os loteamentos dos balneários, que se interligam ao rio Guaraguaçu através de um canal artificial que segue o antigo curso do rio Pery, despejando estes efluentes diretamente no trecho médio da bacia (Figura 2).

Outro importante serviço ambiental desta bacia é representado pelo seu papel ecológico nesta importante região: Interligando duas unidades de conservação de proteção integral (Parque Nacional Saint-Hilaire/Lange e a Estação Ecológica do Guaraguaçu) à Baía de Paranaguá, o contínuo fluvial do Guaraguaçu significa um importante corredor de biodiversidade entre a mata atlântica e o estuário, sendo esta conectividade fundamental para o fluxo gênico e a saúde de diversas comunidades de animais e plantas aquáticas. Tem influência direta no aporte de substâncias biogênicas e minerais à baia de Paranaguá, influenciando portanto na produtividade primária do estuário e consequentemente no estoque pesqueiro, importante item da economia regional. Seu trecho final, interligado aos mangues da Baía de Paranaguá, funciona como um verdadeiro berçário de peixes e como corredor de aves e mamíferos. A manutenção destas funções ecológicas é vital para a pesca e para o turismo na região, sendo que qualquer alteração em sua qualidade ou no fluxo de substâncias biogênicas para o estuário podem ter graves consequências a estas atividades econômicas, além da evidente probabilidade de contaminação de alimentos e disseminação de vetores epidemiológicos. 


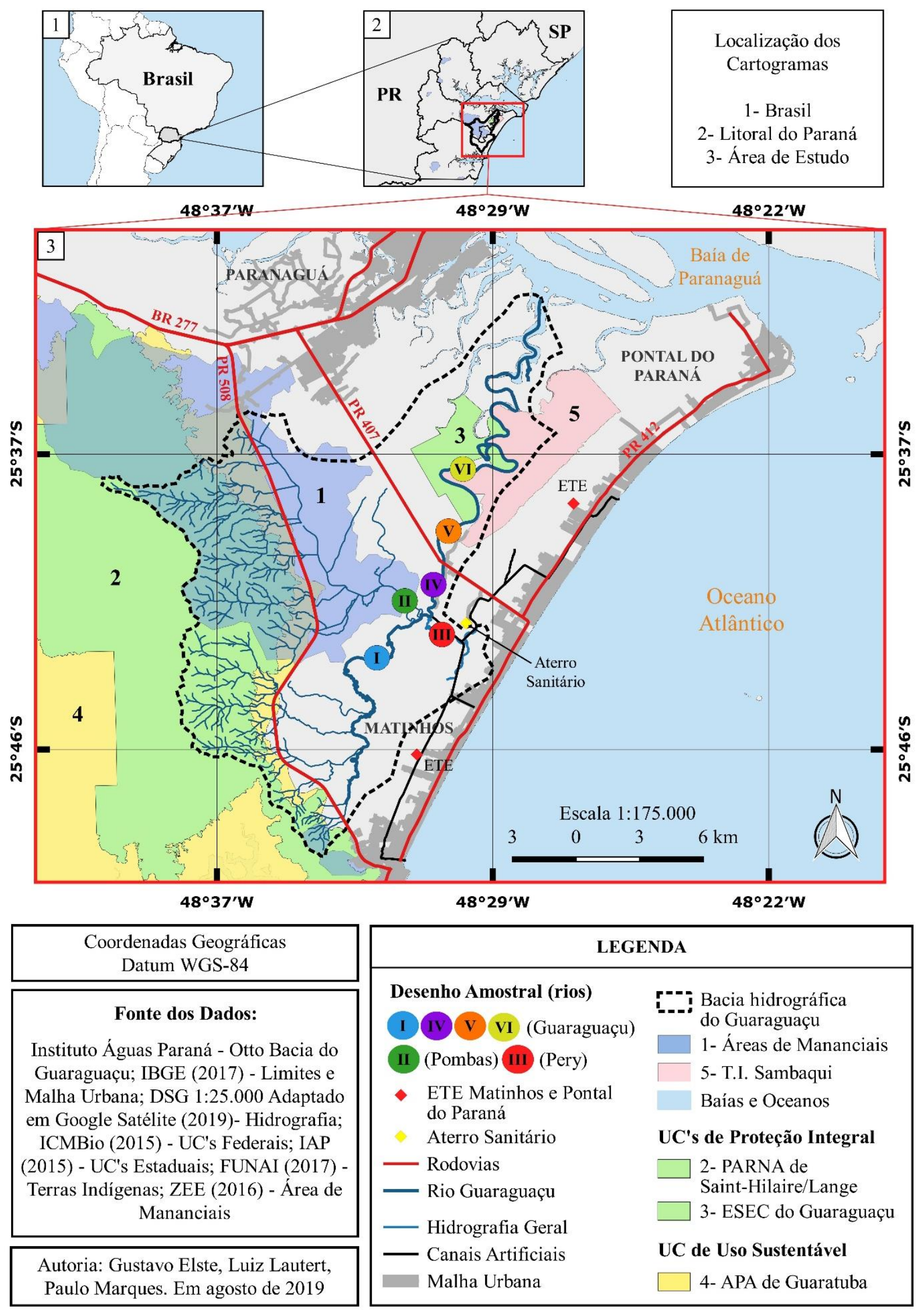

FIGURA 1: CARTOGRAMA DA ÁREA DE ESTUDO, COMPOSTO PELO DESENHO AMOSTRAL COM 6 PONTOS DE COLETA DISTRIBUÍDOS NO RIO GUARAGUAÇU E AFLUENTES; PELAS ÁREAS DE MANANCIAIS; PELAS UNIDADES 
DE CONSERVAÇÃO; PELA TERRA INDÍGENA E PELAS ÁREAS URBANAS DOS MUNICÍPIOS DE MATINHOS, PARANAGUÁ E PONTAL DO PARANÁ.

ORGANIZAÇÃO: Gustavo A. S. Elste, Luiz C. Lautert e Paulo H. C. Marques, 2019.

\section{O problema ambiental diagnosticado}

O rio Pery, originalmente um pequeno afluente do Guaraguaçu, de padrão meândrico típico da planície, que teve seu traçado retificado e foi interligado a rede de drenagem de canais artificiais do Departamento Nacional de Obras de Saneamento (DNOS) que se estende por toda a faixa dos balneários dos municípios de Pontal do Paraná e Matinhos. Além de receberem os efluentes da estação de tratamento de esgotos destes dois municípios (ver localização na fig. 1), os canais drenam extensas áreas ainda não atendidas por rede de esgoto, recebendo também uma grande carga poluidora difusa, sendo intensamente eutrofizados. Conforme o aumento da urbanização, os canais abertos inicialmente para drenar terrenos a serem loteados nos balneários, sofreram gradativamente processos de assoreamento e eutrofização, e a solução de engenharia encontrada foi interligar o sistema de drenagem ao curso do Guaraguaçu, evitando que os efluentes prejudicassem a balneabilidade das praias se fossem direcionados ao mar. Assim, o pequeno rio Pery transformou-se em um grande sistema hidrográfico de canais artificiais que recebe praticamente toda a carga poluidora pontual e difusa das áreas urbanas dos dois municípios.

Próximo ao canal artificial do rio Pery, foi implantado o Aterro Sanitário de Pontal do Paraná, distante a aproximadamente 1,5 km da PR 407, na altura do posto da Polícia Rodoviária Estadual, a aproximadamente 4 quilômetros da praia. Na estrada de terra que dá acesso ao aterro sanitário surgiu um bairro que possuí abastecimento de água municipal e energia elétrica, sendo que o tratamento de esgoto é feito quase sempre na forma de fossas sépticas (RASSOLIN, 2002).

Este aterro possui uma área total de 242.595,82 $\mathrm{m}^{2}$ dos quais $111.507,00 \mathrm{~m}^{2}$ são destinados às seis células de deposição de lixo previstas e o restante é ocupado pela barreira verde, anel viário, sistema de tratamento de efluentes, pátio de materiais, galpão, balança, escritório, refeitório e banheiros (RASSOLIN, 2002). O aterro sanitário é utilizado pelos municípios de Pontal do Paraná e Matinhos, coordenado por um consórcio (CIAS - Consórcio Intermunicipal Aterro Sanitário) e começou a ser operado em fevereiro de 2000. Segundo o seu memorial descritivo, ele foi projetado para uma vida útil de no mínimo 15 anos podendo chegar a mais de 20 anos e atingindo um máximo de $150 \mathrm{~m}$ de comprimento e largura, e $15 \mathrm{~m}$ de altura (CIAS, 2008).

Conforme descrito, além de receber a carga poluidora dos esgotos tratados ou não, a microbacia também foi o destino de todo o lixo urbano coletado nestes municípios nas últimas décadas. Próximo ao final de sua vida útil, e tão próximo ao curso do rio Pery, em solo tão permeável, 
não é de se espantar que começasse a produzir seus efeitos ambientais deletérios, conforme nossos resultados demonstram adiante.

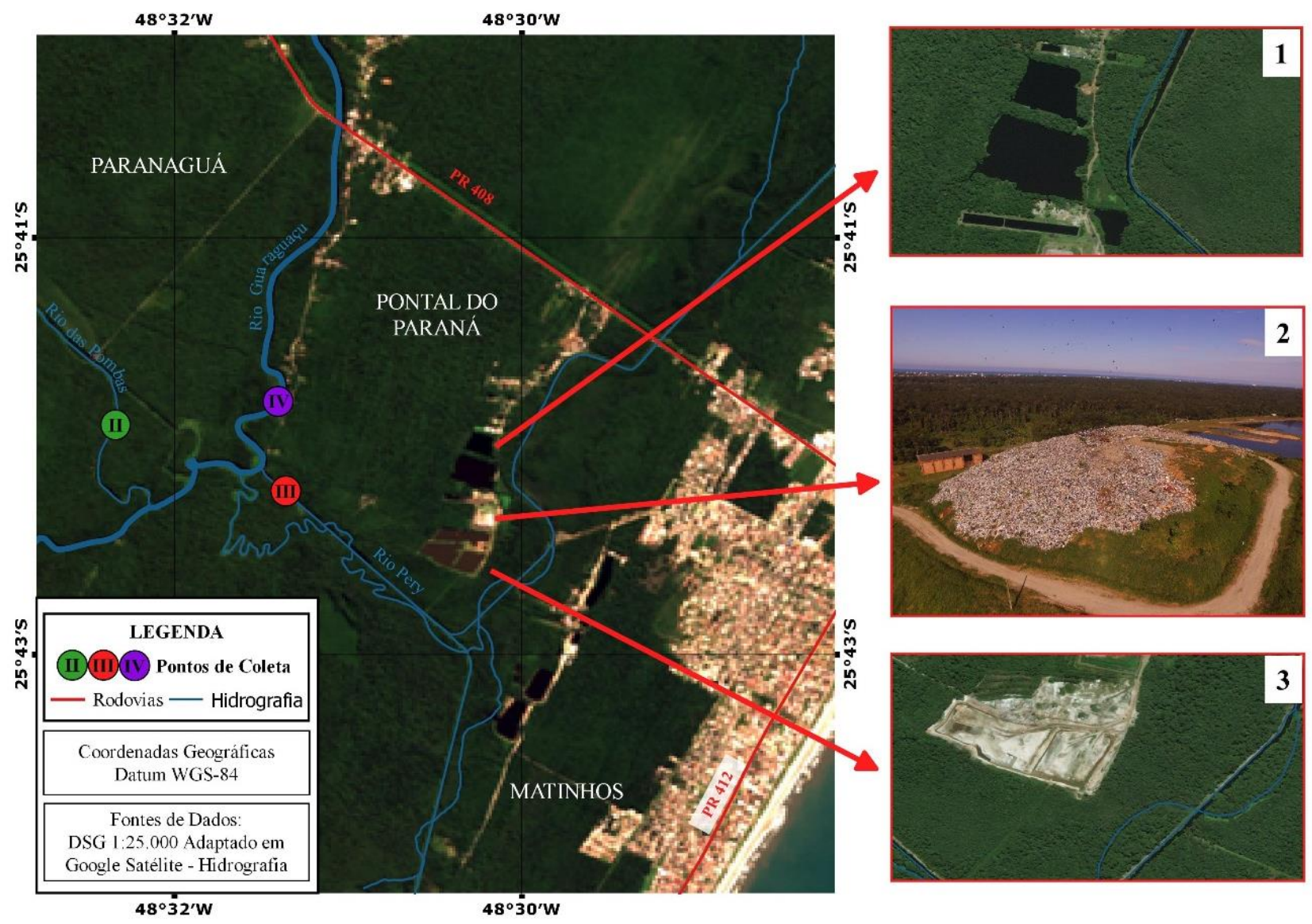

FIGURA 2: LOCALIZAÇÃO DA CONFLUÊNCIA ENTRE O RIO GUARAGUAÇU E SEUS DOIS AFLUENTES (POMBAS E PERY). EM DESTAQUE O ATERRO SANITÁRIO DOS MUNICÍPIOS DE MATINHOS E PONTAL DO PARANÁ REPRESENTADO PELA CÉLULA DE RESÍDUOS E SEUS TANQUES DE TRATAMENTO.

FONTE: MAPA 1 (SENTINEL-2, 2019) OBTIDA EM WWW.EOS.COM/LANDVIEWER; IMAGEM 2 (CORREA, 2019), OBTIDA POR VÔO DE DRONE EM 27 MAIO DE 2019, IMAGENS 1 E 3 (BING SATÉLITE).

ORGANIZADORES: Gustavo Elste e Paulo Marques (2019).

\section{Procedimentos}

Os estudos de campo e coletas de águas superficiais, foram realizados nos dias 10 e 22 de maio de 2019, com deslocamento por meio de barco entre 6 pontos distribuídos ao longo do trecho médio e final do rio Guaraguaçu e na foz de seus afluentes principais, Pombas e Pery (Figura 1 e Figura 2). As análises laboratoriais foram realizadas no Laboratório de Análises Ambientais do Setor Litoral da Universidade Federal do Paraná.

As variáveis analisadas foram: Transparência de Secchi $(\mathrm{m}), \mathrm{pH}$, Condutividade $\left(\mu \mathrm{S} . \mathrm{cm}^{-1}\right)$, Oxigênio Dissolvido - OD (mg.L $\left.\mathrm{L}^{-1}\right)$, Demanda Bioquímica de Oxigênio - DBO $5\left(\mathrm{mg} . \mathrm{L}^{-1}\right)$, Seston (mg.L $\left.L^{-1}\right)$ e os nutrientes: Fosfato - $\mathrm{PO}_{4}\left(\mu \mathrm{g} . \mathrm{L}^{-1}\right)$, Amônio - $\mathrm{NH}_{4}\left(\mu \mathrm{g} . \mathrm{L}^{-1}\right)$, Nitrito - $\mathrm{NO}_{2}\left(\mu \mathrm{g} . \mathrm{L}^{-1}\right)$, e 
Silicato - $\mathrm{Si}(\mathrm{OH})_{4}\left(\mu \mathrm{g} . \mathrm{L}^{-1}\right)$. O Secchi, o $\mathrm{pH}$ e a Condutividade foram aferidos em laboratório, no momento de chegada do campo. As amostras de OD e de $\mathrm{DBO}_{5}$ foram coletadas em frascos apropriados e transportadas até o laboratório em caixa térmica sob temperatura ambiente (água do rio), o OD foi fixado no momento da coleta e analisado no mesmo dia, enquanto a amostra de $\mathrm{DBO}_{5}$ foi incubada e analisada no quinto dia após a coleta, ambas pelo método de Winkler (1988). As amostras de nutrientes foram coletadas em frascos apropriados de polietileno e também transportadas em condições apropriadas até o laboratório e congeladas. Após descongelamento das mesmas foram realizados procedimentos de análise por meio do espectrofotometria.

\section{Resultados e discussão}

Na figura a seguir (Figura 3), foi organizada a apresentação de todos os resultados de campo em forma de gráficos em colunas, facilitando sua visualização conjunta. Os dados representam a média aritmética dos valores obtidos nas duas coletas, com suas respectivas réplicas, como um "retrato" da qualidade das águas para o período, ressaltando o fato de que as coletas foram realizadas ainda em período de alta pluviosidade, o que permite levantar a hipótese de que nos períodos de estiagem os padrões sejam ainda mais evidentes, pois o menor volume de água pode concentrar ainda mais os contaminantes. 


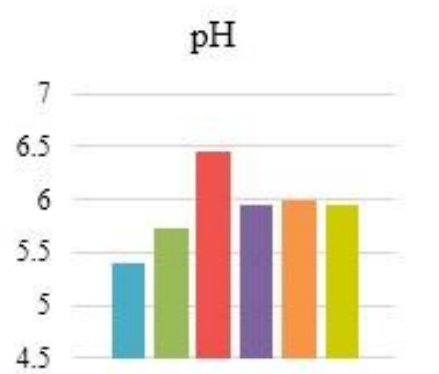

O.D. $\left(\mathrm{mg} / \mathrm{L}^{-1}\right)$
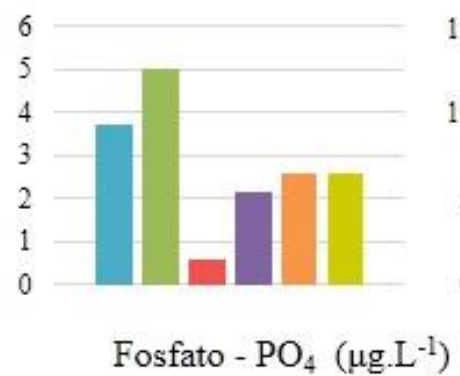

250

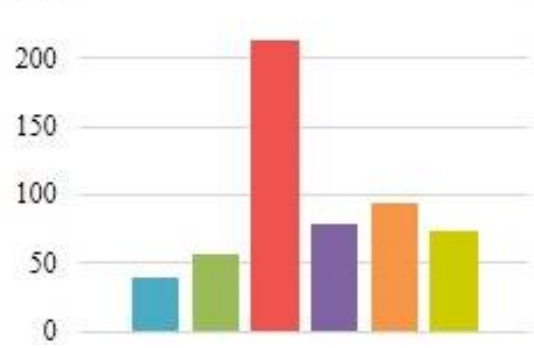

Condutividade $\left(\mu \mathrm{S} . \mathrm{cm}^{-1}\right)$

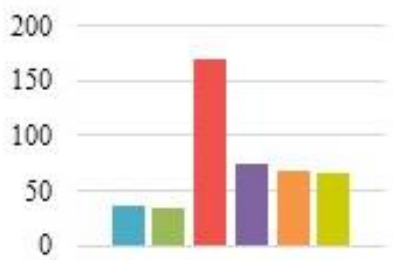

D.B.O. $\left(\mathrm{mg} / \mathrm{L}^{-1}\right)$
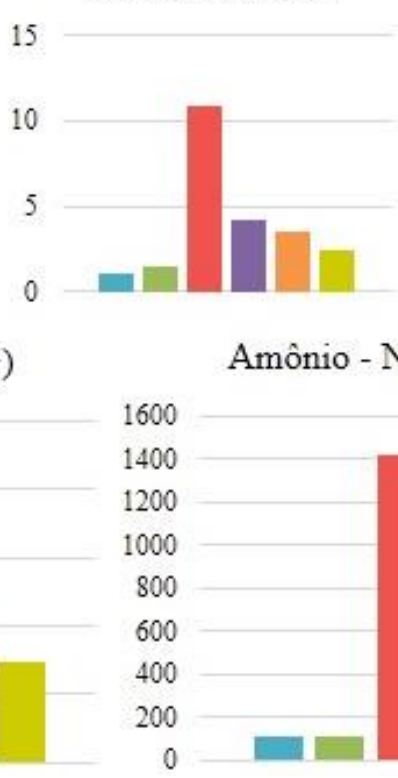
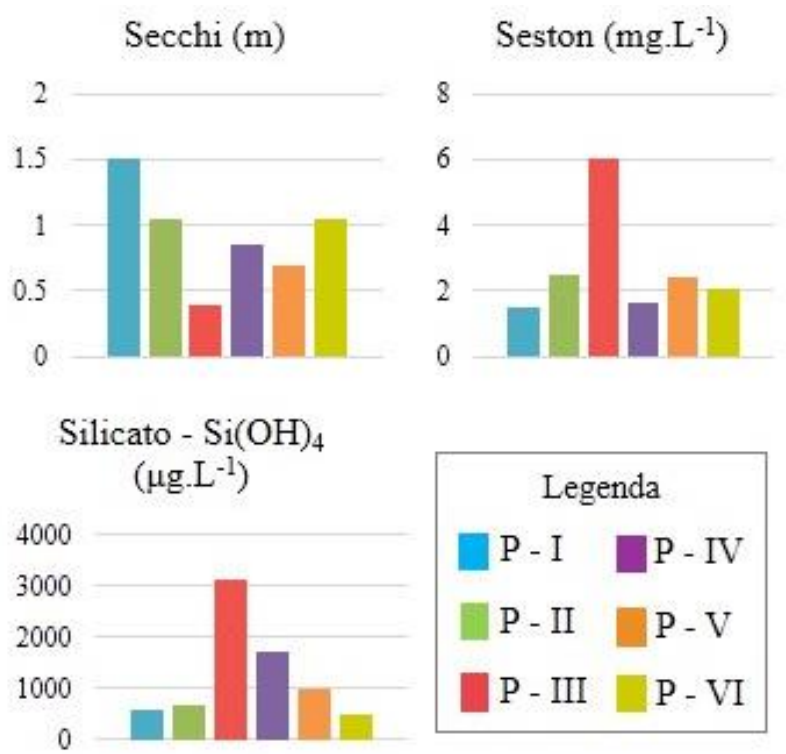

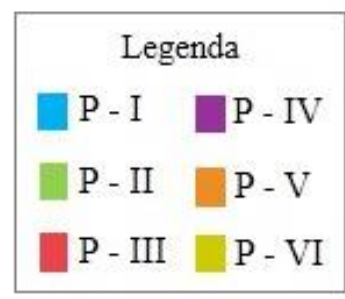

FIGURA 3: PRANCHA DE GRÁFICOS APRESENTANDO O COMPORTAMENTO DAS 10 VARIÁVEIS LIMNOLÓGICAS: PH, CONDUTIVIDADE, SECCHI, SESTON, OD, DBO, SILICATO (SI(OH)4), FOSFATO $\left(\mathrm{PO}_{4}\right)$, AMÔNIO $\left(\mathrm{NH}_{4}\right)$, NITRITO $\left(\mathrm{NO}_{2}\right)$, EM FUNÇÃO DOS PONTOS AMOSTRAIS (I, II, III, IV, V, VI), LOCALIZADAS NOS RIOS GUARAGUAÇU E SEUS AFLUENTES (FIGURA 1).

FONTE: os autores.

\section{Características limnológicas}

O ambiente lótico retratado corresponde ao trecho final da Bacia do Guaraguaçu que adquire características bastante distintas dos trechos a montante, onde o ambiente é altamente influenciado pela serra do mar. Ao encontrar o barramento geomorfológico formado pelos cordões litorâneos característicos da planície costeira descritos em Angulo (1992), a drenagem da bacia desvia-se ao norte em direção à baía de Paranaguá, determinando uma extensa planície de inundação, onde o rio se estende em padrão meândrico, formando lagoas marginais, áreas alagadas. No trecho final, temos ainda um ambiente praticamente estuarino, com influência da salinidade e do represamento determinado pelas variações da maré. Em todo este trecho, que é o maior rio de planície da região, temos um substrato de sedimentos finos e lodo, típico das áreas de deposição. As características geomorfológicas nos levam a concluir que este ambiente seja mais influenciado pela Dimensão Lateral, na concepção de Ward (1994), em que as interações entre o canal e a planície adjacente, 
através de um regime de inundações periódicas e da conectividade a um lençol freático superficial e altamente permeável, pode ser mais determinante nas características limnológicas do que a dimensão longitudinal. O material biogênico importado de rio acima se deposita e há predomínio de processos locais de produção, decomposição e reciclagem biogênica. Como características gerais, os dados mostram: ambiente com pH mais ácido, em decorrência da decomposição de matéria orgânica, com a típica coloração dos ácidos orgânicos (cor de coca-cola), diminuição do material particulado. A baixa velocidade da corrente determina um ambiente intensamente propício à acumulação de substâncias no sedimento, processos de eutrofização e magnificação biológica. Tais fenômenos são abordados em outro estudo deste grupo de pesquisa, onde analisada a relação da população de Lontra longicaudis (OLFERS,1818), mamífero que está no topo da cadeia trófica deste ambiente, com as características limnológicas dos diferentes trechos da bacia (ZANLORENCI et al. 2019).

As características encontradas nos pontos I e II deste gradiente longitudinal podem ser tomadas como uma referência do que seria o ambiente lótico de todo o trecho final da bacia sem a interferência antrópica. As variáveis provavelmente apresentariam um suave gradiente positivo ou negativo em direção ao estuário.

\section{Os Efeitos do rio Pery no Contínuo Fluvial do rio Guaraguaçu}

Corroborando a hipótese que motivou o estudo, verificamos uma profunda diferença entre as variáveis dos pontos I e II e as do ponto III (rio Pery), e esta diferença produz modificação em praticamente todos as variáveis do rio Guaraguaçu a jusante deste afluente. Podemos concluir que o rio Pery provoca uma profunda alteração no contínuo fluvial do Guaraguaçu, que se estende por todo o trecho final, determinando uma Descontinuidade Serial, conforme Stanford e Ward (2001), de grande magnitude, conforme segue.

Destacamos, entre os resultados, os baixíssimos níveis de OD $(0,56 \mathrm{mg} / \mathrm{L})$, que somado aos altos níveis de $\mathrm{DBO}_{5}$ (acima de $10 \mathrm{mg} / \mathrm{L}$ ) no rio Pery, denotam inequívoca influência de efluentes sanitários e justificam as reclamações de mau cheiro e morte de peixes anotadas pela população. É altamente provável que ocorram episódios de ANOXIA, (constatada em uma das réplicas amostrais) conforme condições climáticas de temperatura e pluviosidade, determinando estes graves efeitos deletérios.

Da mesma forma, percebeu-se entre os nutrientes analisados, os altos níveis dos íons fosfato $\left(\mathrm{PO}_{4}\right)$ e amônio $\left(\mathrm{NH}_{4}\right)$, também relacionados a poluição deste tributário. Em ambientes aquáticos continentais, e sobretudo nos rios da Mata Atlântica, os nutrientes fosfatados são naturalmente escassos, sendo considerados um fator limitante à produtividade geral do ecossistema. Qualquer 
aporte de fosfatos torna-se bastante importante, sendo um dos fatores que mais pode determinar a eutrofização do ambiente. A amônia, que também pode ser considerada como um nutriente, conforme as condições de nitrificação ou desnitrificação bacteriana, e seus níveis de concentração, pode ser altamente tóxica à comunidade aquática. Os níveis de silicato, que normalmente iriam decaindo neste trecho, também sofre as consequências do rio Pery, mas nesse caso podem ser mais relacionados à intensa atividade de mineração de areia na região.

De acordo com a Resolução n. ${ }^{\circ}$ 01/86 do CONAMA, é considerado impacto ambiental:

Qualquer alteração das propriedades físicas, químicas e biológicas do meio ambiente, causada por qualquer forma de matéria ou energia resultante das atividades humanas que, direta ou indiretamente, afetam: (1) a saúde, a segurança e o bem-estar da população; (2) as atividades sociais e econômicas; (3) a biota; (4) as condições estéticas e sanitárias do meio ambiente; (5) a qualidade dos recursos ambientais (BRASIL, 1986).

Uma das formas de se compreender o comportamento dos ecossistemas aquáticos é através dos seus aspectos físico-químicos. O conceito de contínuo fluvial (RCC) cunhado por Vannote (1980) mostra que o perfil longitudinal (montante/jusante) do sistema fluvial apresenta um gradiente contínuo de condições físicas que respondem diretamente na composição da flora e fauna bentônica, e resulta num contínuo de adaptações bióticas e padrões consistentes de carga, transporte, utilização e armazenamento da matéria orgânica ao longo do comprimento do rio (THORP et al., 2008).

Baseado no RCC, Stanford e Ward (2001), cunharam o conceito de descontinuidade serial (SDC), que foi direcionado ao estudo de impacto do ambiente hídrico e aborda as consequências da introdução da Descontinuidade Serial (quebra do contínuo) no sistema fluvial, refletindo diretamente na estrutura das comunidades e processos ecológicos adjacentes. Dessa forma os resultados permitem concluir que o rio Pery representa um impacto ambiental de grande magnitude, pois ao longo do trecho a jusante o rio Guaraguaçu não retorna às condições encontradas a montante do ponto de descontinuidade claramente identificado.

\section{Evidências da contaminação a partir do Aterro Sanitário}

Conforme exposto, o rio Pery recebe uma grande carga orgânica do sistema de canais artificiais, incluindo efluentes de estação de tratamento de esgotos antes de atravessar a região final de seu curso, onde está o aterro sanitário. Entretanto, comparando os resultados aqui expostos, com estudos anteriores e relatórios de impacto ambiental que produziram dados de qualidade da água nestes canais, e também no sistema hidrográfico do rio Matinhos, verifica-se que as condições de contaminação da água no trecho amostrado a jusante do Aterro Sanitário são expressivamente piores, 
demonstrando que o aterro pode ser a fonte principal de contaminação do canal e, consequentemente, do rio Guaraguaçu.

Figueirêdo (2008) em sua dissertação de mestrado intitulada "Caracterização físico-química e microbiológica da lagoa de polimento e das lagoas do entorno do aterro sanitário de pontal do paraná”, encontrou naquela época dados de qualidade da água com as mesmas metodologias aqui utilizadas que mostram que o ambiente limnológico no interior dessas lagoas era mais saudável do que o que encontramos hoje no rio Pery. Disto conclui-se que o aterro, já no limite de sua vida útil prevista, passou a contaminar fortemente o lençol freático e os cursos d'água do seu entorno nos últimos anos, constituindo talvez o maior passivo ambiental desta região. Com efeito cumulativo, mesmo que o aterro seja desativado, medidas de controle terão que ser adotadas, pois o efeito deletério deve continuar por muitos anos.

Ressalta-se ainda que este estudo abordou apenas algumas variáveis limnológicas, com o objetivo de avaliar a influência do rio Pery e do Aterro Sanitário no contínuo fluvial da bacia do Guaraguaçu, fato amplamente demonstrado pelos resultados. Dada a natureza dos rejeitos que poluem o rio Pery, desde efluentes sanitários aos mais diversos resíduos que compõem o lixo urbano, é de se esperar que diversos outros contaminantes estejam presentes em altos níveis, tais como: metais pesados, antibióticos, hormônios, inseticidas e outros biocidas, diversos agentes etiológicos microbiológicos entre outras possibilidades, como nos mostra vasta literatura científica a respeito. Cavallini et al., (2018), encontraram contaminação de fezes de Lontra longicaudis, um mamífero topo de cadeia trófica neste ambiente, por metais pesados, especialmente cádmio $(\mathrm{Cd})$, chumbo $(\mathrm{Pb})$ e manganês (Mn), mostrando que os processos de contaminação da biota e magnificação biológica já são evidentes e de grande magnitude.

\section{Considerações finais}

Os resultados apresentados descrevem uma situação de enorme passivo ambiental e grave risco, e este trabalho sugere a urgência de estudos mais aprofundados, com as seguintes indagações: Quais os poluentes estão presentes e qual o seu risco aos ecossistemas e populações humanas? O aterro Sanitário tem condições de evitar essa contaminação? Que alternativas podemos planejar? Assim, apontamos algumas considerações a respeito de duas questões relativas às políticas públicas ambientais e aos planos de desenvolvimento projetados para a região: 


\section{O Plano da Bacia Hidrográfica Litorânea}

O novo enquadramento dos cursos d'água do litoral, construído pelo recém implantado Comitê da Bacia Litorânea através de contrato celebrado entre o Instituto Águas Paraná e a Companhia Brasileira de Projetos e Empreendimentos (COBRAPE), encontra-se em fase de aprovação pelo Comitê Estadual de Recursos Hídricos. Este planejamento propõe o enquadramento da Bacia do Guaraguaçu conforme disposições da Resolução CNRH nº 91/08 (BRASIL, 1998): os trechos superior e médio da bacia, onde situam-se as regiões dos mananciais de abastecimento, em Classe 1 e Classe Especial; à jusante da captação de água que delimita a área de mananciais, o rio Pery, em Classe 2; ao longo do Guaraguaçu, a existência de unidades de conservação de proteção integral (ESEC do Guaraguaçu), terras indígenas (TI Sambaqui) e comunidades ribeirinhas, tornou obrigatório, conforme a legislação, o enquadramento em Classe Especial. A proposta considerou também a importância ecológica do rio Guaraguaçu para a produtividade pesqueira geral da Baía de Paranaguá, especialmente para as comunidades ribeirinhas do Guaraguaçu e Maciel, que tem grande parte de sua renda proveniente da pesca neste estuário. O presente estudo demonstrou que, ao perdurar o foco de contaminação no rio Pery, tal proposta de enquadramento está em risco de não ser atingida antes mesmo de entrar em vigor. Pois todos as variáveis que extrapolaram os parâmetros previstos pelas Classes do enquadramento proposto, constituem a medida exata do passivo ambiental criado.

\section{O projeto de desenvolvimento Regional}

O planejamento para esta região com apoio do Governo Estadual e prefeituras municipais, denominado "Faixa de Infraestrutura de Pontal do Paraná", prevê a construção de uma nova estrada interligando praia de Leste a Pontal do Sul para favorecer a interligação da atividade industrial e portuária de Paranaguá a um novo porto a ser construído em Pontal do Paraná. Os estudos de Impacto Ambiental do empreendimento mostram um incremento considerável na população residente e expansão das áreas urbanas em regiões mais próximas ao rio Guaraguaçu, além das referidas atividades industriais e portuárias, nas quais, obviamente, acarretarão no aumento da carga orgânica despejada pelas estações de tratamento de esgoto e pela poluição difusa das áreas ainda sem saneamento básico. Para dimensionar o tamanho do conflito, basta citar que a questão do saneamento básico foi totalmente ignorada por este plano de desenvolvimento, bem como pelo EIA/Rima do Porto.

Por fim, concluímos que este problema ambiental aqui evidenciado e denunciado, pode ser considerado o principal fator limitante aos projetos de desenvolvimento territorial da região, e 
recomendamos fortemente a atenção dos poderes públicos à questão do saneamento, um componente que deve ser urgentemente revisto e incorporado aos processos de planejamento territorial.

\section{Agradecimentos}

Ao Dilson Nazário pela gentileza de nos conduzir em sua embarcação, o Ventania, que foi fundamental para viabilidade no deslocamento entre os pontos de coleta. Ao Alan D'Oliveira Correa por nos ceder as fotografias aéreas e atualizadas, que nos possibilitou melhor compreensão do estudo. Nosso muito obrigado!

\section{Referências}

AB'SABER A. N. Os domínios de natureza no Brasil - Potencialidades paisagísticas. Ateliê Editorial. São Paulo. 2003.

ÁGUAS PARANÁ - INSTITUTO DAS ÁGUAS DO PARANÁ; COBRAPE. Plano da Bacia Hidrográfica Litorânea - Produto 01: Caracterização Geral. Revisão Final. 2019. Disponível em: <https://drive.google.com/file/d/1JGWQYuRIZImT3zheVTjlVysjHolFKRni/view>. Acesso em: Agosto de 2019.

Angulo, R. J. Geologia da Planície Costeira do Estado do Paraná. Tese (Doutorado em Geologia Sedimentar), Universidade de São Paulo - Instituto de Geociências. São Paulo. 1992.

BIGARELLA, J. J.; KLEIN, R.; LOYOLA E SILVA, J.A.; PASSOS, E. A Serra do Mar e a Planície Costeira do Paraná: Um problema de segurança ambiental e nacional. GCN/CFH/UFSC. Florianópolis, 2008.

BRASIL. Conselho Nacional de Recursos Hídricos. Resolução n 91, de 5 de novembro de 2008. Dispõe sobre os procedimentos gerais para o enquadramento dos corpos d'água superficiais e subterrâneos. Brasília. 2008.

BRASIL. Conselho Nacional do Meio Ambiente. Resolução n.001, de 23 de janeiro de 1986. Dispõe sobre critérios básicos e diretrizes gerais para o Relatório de Impacto Ambiental - RIMA. Diário Oficial da República Federativa do Brasil. Brasília. 1986.

CAVAllini, N. G. Contaminação ambiental na bacia do rio Guaraguaçu: determinação quantitativa de contaminantes inorgânicos e diagnóstico a partir de bioindicador. Dissertação (Mestrado em Ciências Ambientais). Universidade Federal do Paraná. Matinhos. 2018.

CORREA, A. O. Fotografias aéreas obtidas por vôo de drone. Realizadas em: 27 de maio de 2019. 
CORRERO DO LITORAL. Aterro de Matinhos e Pontal virou lixão, denunciam promotores. Guaratuba. Redação: Correio do Litoral. 2018. Disponível em: <https://www.correiodolitoral.com/15274/aterro-de-matinhos-e-pontal-virou-lixao-denunciampromotores/>. Acesso em: Agosto de 2019.

DEAN, W. A ferro e Fogo - A História e a devastação da Mata Atlântica brasileira. São Paulo, Companhia das Letras. 1996.

FIGUEIRÊDO, C. S. Caracterização físico-química e microbiológica da lagoa de polimento e das lagoas do entorno do aterro sanitário de pontal do paraná. Dissertação (Mestrado em Sistemas Costeiros e Oceânicos, do Centro de Estudos do Mar, Setor de Ciências da Terra) Universidade Federal do Paraná. Pontal do Paraná. 2008.

FUNDAÇÃO SOS MATA ATLÂNTICA. Observando os rios 2017 - O retrato da qualidade da água nas bacias da Mata Atlântica. Relatório Técnico. 2017. Disponível em: <https://www.sosma.org.br/wp-content/uploads/2016/03/SOSMA_Observando-os-Rios2017_online.pdf>. Acesso em: Julho de 2019.

ITCG. Instituto de Terras, Cartografia e Geologia do Paraná. Mapa do Clima do Estado do Paraná. Dados e informações geospaciais temáticos. 2008. Disponível em: <http://www.itcg.pr.gov.br/arquivos/File/Produtos_DGEO/Mapas_ITCG/PDF/Mapa_Climas_A3.p df $>$. Acesso em março de 2017.

LADEIRA, M. I., Espaço geográfico Guarani-Mbya: significado, constituição e uso. Maringá: EDUEM, 2008.

MARQUES, P.H.C. Água e sustentabilidade territorial: conflitos e limites dos mananciais da serra da prata (Litoral do Paraná) frente a políticas públicas e projetos de desenvolvimento regional. Anais do II SIMPÓSIO BRASILEIRO DE DESENVOLVIMENTO TERRITORIAL SUSTENTÁVEL. Matinhos. 2017. Disponível em: <http://www.ppgdts.ufpr.br/?page_id=1464>. Acesso em Julho de 2019.

MIRETZKI, M. As águas do Parque Nacional de Saint-Hilaire/Lange: o uso de metodologias para o monitoramento da microbacia do rio Ribeirão, Litoral do Paraná. Dissertação (Mestrado em Desenvolvimento Territorial Sustentável) - Universidade Federal do Paraná - Setor Litoral. Matinhos. 2017.

PIRES, A. P. F.; FARJALlA, V. F.; FARIA, B M.; RODRIGUEZ, D. A.; GOMES, E. A. T.; SANTOS, E. C.; SODRÉ, F. N. G. A. S.; SABINO, J.; ESPÉCIE, M.A.; PINHEIRO, M. R. C.; RIBEIRO, M. L.; BOZELLI, R. L.; PANOSSO, R. F.; MORMUL, R. P.; BARTHEM, R.; SCOFIELD, V.; DIB, V. Sumário para Tomadores de Decisão (STD) do Relatório Temático Água: biodiversidade, serviços ecossistêmicos e bem estar humano no Brasil. São Carlos: Editora Cubo. 2019.

PIRES, P. T. L. Atlas da Floresta Atlântica no Paraná. SEMA/Programa proteção da Mata Atlântica. Curitiba. 2005.

RASSOLIN, P. Proposta de um modelo de manejo de resíduos sólidos no litoral paranaense: estudo de caso consórcio intermunicipal aterro sanitário. Monografia de Conclusão de Curso em Ciências biológicas, Universidade Federal do Paraná, 67 p. 2002. 
REZENDE, C.L.; SCARANO F.R.; ASSAD E.D.; JOLY C.A.; METZGER J.P.; STRASSBURG B.B.N.; TABARELLI M.; FONSECA G.A.; MITTERMEIER R.A. From hotspot to hopespot: An opportunity for the Brazilian Atlantic Forest. Perspectives in Ecology and Conservation (PECON), 2018. Disponível em: <https://doi.org/10.1016/j.pecon.2018.10.002>. Acesso em Janeiro de 2019.

RODERJAN, C. V.; GALVÃO, F.; KUNYOSHI, Y. S. HATSCHBACH, G. G. As Unidades Fitogeográficas do Estado do Paraná. Ciência \& Ambiente. Santa Maria, v. 24, n. 1. 2002.

STANFORD JA, WARD JV. Revisiting the serial discontinuity concept. Regulated Rivers: Research and Management. 17: 303 - 310. 2001.

THORP, J. H.; THOMS, M. C.; DELONG, M. D. The riverine ecosystem synthesis: toward conceptual cohesiveness in river science. Amsterdam: ELSEVIER, xv, 208p. 2008.

TUNDISI, J.G. Ciclo hidrológico e gerenciamento integrado. Ciência e Cultura. São Paulo. 2003.

VANNOTE, R. L.; MINSHALL, G. W.; CUMMINS, K. W.; SEDELL, J. R.; CUSHING, C. E. The River Continuum Concept. Canadian Journal of Fisheries and Aquatic Science, 37, p. 130-137. 1980.

VANHONI, F.; MENDONÇA, F. O clima do litoral do estado do Paraná. Revista Brasileira de Climatologia, v. 3/4, p. 49 - 63, 2008.

WARD J.V. The four-dimensional nature of lotic ecosystems. Journal of the North American Benthological Society, 8, 2-8, 1989.

ZANLORENCI, G. A. Estudo limnológico de ambientes fluviais de Lontra longicaudis (OLFERS, 1818) na Bacia do rio Guaraguaçu, Litoral do Paraná. Anais do III SIMPÓSIO BRASILEIRO DE DESENVOLVIMENTO TERRITORIAL SUSTENTÁVEL. Matinhos. 2019.

ZEE. Zoneamento Ecológico Econômico do Litoral do Paraná. Decreto Estadual n 4.996 de 05 de setembro de 2016. Curitiba. 2016.

Artigo recebido em 01/12/2019. Aceito para publicação em 19/12/2019. 